\title{
Os candidatos ainda evitam a interação? Twitter, Comunicação Horizontal e Eleições Brasileiras
}

\section{Camilo De Oliveira Aggio}

\section{Resumo}

Ao longo da constituição da literatura sobre

campanhas online, o tema da interação tornou-se

um dos mais relevantes, e pesquisas empíricas

demonstraram que os candidatos tenderam a evitar a

interação direta com eleitores ao longo dos anos e em

diferentes países, conforme esboçou a pesquisadora

Jennifer Stromer-Galley em 2000. Este trabalho

pretende discutir as mudanças potenciais e efetivas

desse panorama com a inserção dos social media

em estratégias de campanha, enfocando na análise

do quão interativos foram os perfis oficiais dos três

principais candidatos a presidente do Brasil em

2010 no Twitter e quais os perfis dos interlocutores

contemplados nessas interações.

\section{Palavras-Chave}

Eleições. Campanhas Online. Twitter.

Camilo De Oliveira Aggio I camiloaggio@gmail.com Doutor em Comunicação e Política pelo Programa de Pós-Graduação em Comunicação e Cultura Contemporâneas da Universidade Federal da Bahia - UFBA. Pesquisa os efeitos sociais e políticos da inserção da comunicação digital em disputas eleitorais.
Por que a discussão sobre a interação direta - e potencialmente dialógica - é relevante para as discussões sobre campanhas políticas, principalmente em ambientes digitais? Essa indagação, em geral, é colocada por pesquisadores que assumem a perspectiva de que campanhas eleitorais são constituídas por um manancial de prioridades estratégicas que colocam o desejo, a reivindicação ou o simples interesse científico em detectar 0 quão dialógicos são ou podem ser partidos e candidatos na internet em um segundo plano de potencial relevância. Trata-se de uma posição crítica legítima e oportuna, mas que, na mesma medida em que acumula muitos méritos, deixa de lançar luz sobre 0 quanto a interação com o público em ambientes digitais pode se constituir em estratégias tão importantes, complementar ou suplementarmente, às outras estratégias tradicionais da comunicação eleitoral, como as políticas de imagem, composição de mensagens persuasivas, gerenciamento de crises, mobilização de militantes, busca pelo voto, correções nas rotas estratégicas, etc.

Em outra perspectiva, a possibilidade da comunicação direta e alargada entre indivíduos, 
grupos e instituições na internet faz com que pesquisadores vislumbrem ganhos democráticos nessa dinâmica potencialmente dialógica entre agentes da política, em disputa eleitoral, e cidadãos.

\section{Interação online e por que os} candidatos a evitam: 0 valor estratégico e democrático da comunicação horizontal e a tendência unidirecional das campanhas online

Jennifer Stromer-Galley é uma das pesquisadoras que se integram a uma perspectiva ampliada sobre a interação em estratégias de campanha, sem perder de vista 0 realismo pragmático das disputas eleitorais. A autora é responsável por um trabalho que organiza pontos centrais da discussão acerca da interatividade nas campanhas online. 0 artigo "Interação on-line e por que os candidatos a evitam", publicado originalmente em 2000, além de trazer uma posição política e teórica embutida na abordagem adotada, também examina os problemas e riscos decorrentes da adoção de mecanismos interativos por campanhas (STROMER-GALLEY, 2013). Ao adotar uma perspectiva simpática ao modelo deliberativo de democracia, a pesquisadora norte-americana elabora um quadro normativo que atribui às campanhas online a capacidade de diminuir 0 distanciamento entre a esfera civil e a esfera política, através de processos dialógicos.

A aproximação entre cidadãos e campanhas se daria em diferentes níveis e com propósitos distintos: esclarecer questões, responder a críticas, discutir projetos, compartilhar sugestões e, em um nível participativo elevado, materializar a construção colaborativa, socialmente ampliada, de uma campanha.

Outros autores sustentam que a abertura das campanhas para 0 debate direto com candidatos e partidos teria a capacidade de reduzir a crescente desconfiança do eleitorado na classe política e a percepção negativa dos cidadãos sobre os efeitos que poderiam exercer na esfera da decisão política. Envolver a cidadania em processos de debate e decisões, portanto, teria a capacidade de reduzir ou sanar os déficits de credibilidade nas instituições democráticas (KAID, POSTELNICU, 2005).

Intrinsecamente, há tensões e negociações entre correntes variadas para decidir os rumos de uma campanha na dinâmica democrática das disputas eleitorais. No entanto, esses processos são circunscritos a uma percentagem pequena de uma dada comunidade política.

Em sociedades massivas, torna-se impossível reunir um contingente expressivo de cidadãos a se representarem em assembleias ou quaisquer outros tipos de reuniões presenciais em que sejam deliberadas questões que apontem nortes para os planos de governo das campanhas. Uma ampla participação civil e presencial nesses processos se torna improvável, mesmo que esse contingente seja restrito àqueles com desejo de participar, mas que, por impedimentos e 
constrições diversas (de tempo disponível ao deslocamento), não podem.

A possibilidade de agrupar cidadãos interessados em debater questões políticas em um fórum de participação promovido por uma campanha em seu website, por exemplo, é muito maior se for considerado que 0 tempo gasto requerido e a ausência da necessidade de deslocamento inexistem nesta modalidade participativa. Em termos representativos, iniciativas de participação online podem ser muito mais ricas se comparadas às iniciativas presenciais. Idealmente, o volume de participação pode ser maior, e outras qualidades de ordem normativa, se presentes nos fóruns de discussão - a exemplo da exposição ininterrupta de argumentos publicados por outros participantes que podem fomentar a reflexividade e reciprocidade - podem elevar o nível de eficiência e riqueza dos processos deliberativos (DAHLBERG, 2001).

Contudo, Stromer-Galley (2013), ao analisar websites dos candidatos Bob Dole e Bill Clinton que concorriam à presidência dos Estados Unidos em 1996, além de websites de 10 candidatos a governos estaduais norte-americanos em 1998, descobriu que os candidatos não desenvolveram iniciativas para dialogar com eleitores - característica que se tornou padrão nas campanhas online ao longo dos anos e em diferentes países (HOWARD, 2005; DAVIS, OWEN, 1998; CARLSON, DJUSPUND, 2001; FARNSWORTH, OWEN, 2004; GIBSON et al.,
2003; KLUVER, 2004; WARD, GIBSON, 2003;

DRUCKMAN et. al, 2007; LUSOLI, WARD, 2005;

PARK, PERRY, 2008; TKACH-KAWASAKI, 2003;

FERNANDEZ, 2005; SCHWEITZER, 2005).

A autora elenca as três principais razões para que a comunicação dialógica não tenha sido adotada, segundo entrevistas com coordenadores das campanhas analisadas: (a) a onerosidade para a manutenção de tais iniciativas; (b) o risco de perda de controle sobre as mensagens de campanha; (c) e o risco da perda da ambiguidade discursiva. No primeiro caso, os gestores das campanhas entrevistados relataram a insuficiência de mão de obra para administrar efetivamente a comunicação direta requisitada por eleitores através de e-mails ou fóruns eletrônicos. No segundo caso, os coordenadores das campanhas relataram temer que adversários atuassem nestes espaços para promover campanha negativa no território do próprio candidato. No último quesito, temia-se que candidatos e membros da campanha fossem compelidos a tocar em pontos delicados de determinadas propostas ou posicionamentos controversos que pudessem desagradar parte de seus eleitores.

\section{Os Social Media e suas apropriações sociais}

A tendência unidirecional das campanhas online, em geral, foi detectada nas fases présocial media, portanto, antes de candidatos e partidos ingressarem nessas arenas de interações 
discursivas, em que a maioria dos que têm acesso à internet gasta seu tempo online manifestandose, consumindo informação e interagindo em diferentes níveis com outros usuários. Antes de sites como Twitter e Facebook, partidos e candidatos atuavam em domínios que lhes eram particulares, como websites ou blogs. Havia um controle sobre quais ferramentas usar, quais recursos empregar e em quais termos a comunicação deveria se estabelecer. 0 advento e a popularização dos sites de redes sociais diluem um pouco esse controle e forçam partidos e candidatos a explorarem um domínio cujas regras, sentidos e práticas são engendrados por uma ampla comunidade de usuários, demandando mais adaptações do que apropriações por parte das campanhas.

A dinâmica comunicativa dos sites de redes sociais, dessa forma, pressupõe considerar 0 que estão fazendo aqueles em sua volta, mas não só: os recursos disponíveis no Twitter e no Facebook foram projetados para que seus usuários interagissem com outros usuários. Comentar, compartilhar, reproduzir mensagens, discutir e avaliar notícias ou publicações originais de terceiros e comunicar-se interpessoalmente em espaços privados são alguns dos instrumentos disponíveis nesses sites e que conformam uma ética comportamental.

Há, assim, um horizonte de expectativas que se estabelece nesses territórios digitais. Se 0 pressuposto fundamental de utilização desses sites é a interação entre seus usuários, existe, normativamente, um constrangimento e dilema posto às campanhas que decidem se aventurar nesses domínios: comportar-se como um usuário comum e, assim, considerar a interação com terceiros, ou adotar um perfil descolado da sociabilidade estabelecida nesses canais, "despersonificando" o candidato.

\section{Twitter, interação e interlocução nas primeiras campanhas brasileiras no Twitter}

As eleições brasileiras de 2010 foram as primeiras em que campanhas eleitorais foram autorizadas a utilizar diversos recursos digitais, como os social media. Isto porque o Tribunal Superior Eleitoral (TSE) vedava, até então, a incorporação de quaisquer recursos que não websites oficiais no instrumental das campanhas digitais. A disputa eleitoral para presidente do Brasil em 2010, portanto, foi a primeira em que campanhas de presidenciáveis brasileiros se aventuraram nas arenas públicas dos sites para redes sociais.

Este trabalho de pesquisa pretende averiguar se e com qual frequência e com quais propósitos os três principais candidatos a presidente em 2010 interagiram, diretamente, com outros usuários do Twitter e qual o perfil dos interlocutores escolhidos. As campanhas online continuam optando pelo modelo unidirecional de comunicação ou este panorama se transforma quando os social media se tornam campos de atuação estratégica? 
Para tanto, foram analisados 3.578 tweets

publicados nos perfis oficiais de Dilma Rousseff

(PT), José Serra (PSDB) e Marina Silva (PV)

entre abril e outubro de 2010, compreendendo as

disputas do $1^{\circ} \mathrm{e} 2^{\circ}$ turnos. A seleção do corpus foi

definida pelas sondagens de opinião realizadas

desde o período de pré-campanha: os três

candidatos lideraram as intenções de voto nas

pesquisas de todos os institutos.

\section{Metodologia}

A metodologia de análise será apresentada em linhas gerais, com o intuito de reservar maior espaço para a apresentação e discussão dos resultados. 0s recursos de menção (mention) e replicação (retweets) são entendidos aqui como recursos para a interação discursiva - ou indícios de que houve interação entre campanhas e outros usuários do Twitter.

Mensagens sem a presença desses recursos foram nomeadas como "broadcasting".

Desse modo, o volume da presença desses recursos em relação ao total de mensagens publicadas gerou o índice do volume de interação das campanhas. Cada tweet contendo os recursos foi categorizado em uma das 12 categorias temáticas para que as funções estratégicas das interações fossem apreendidas. São elas: (a) agenda; (b) exibição de capital político; (c) exibição de capital social; (d) posicionamento; (e) divulgação de notícias; (f) campanha negativa; (g) tentativa de criar engajamento; (h) pessoal e intimidade; (i) promessas e propostas; (j) realizações passadas; (l) outros.

Essas categorias foram criadas por Gomes et al. (2011) e adaptadas para esta pesquisa. A título de esclarecimento, faz-se necessário afirmar que a categoria "outros" se refere a mensagens relativas a temas informais, a trivialidades que não se encaixam em nenhuma das 11 categorias restantes, embora, sem dúvidas, possam cumprir uma função estratégica.

Posteriormente, foram identificados e categorizados os perfis dos interlocutores contemplados nas mensagens contendo os recursos para a interação discursiva. Para tanto, foram criadas cinco categoriais para determinar quais estratégias de interlocução foram empregadas pelas campanhas. 0 objetivo foi 0 de verificar se as campanhas privilegiaram interagir com cidadãos comuns, políticos, celebridades, jornalistas ou se, porventura, contemplaram perfis "fakes" criados por partidos, militantes ou simpatizantes para simular um caráter interativo das campanhas.

Basicamente, foram separados perfis de agentes e instituições da política, celebridades, cidadãos 
(eleitores, simpatizantes e militantes), agentes e agências do jornalismo (jornalistas, contas de veículos de comunicação, blogs independentes), "fakes" e "outros" (grupos organizados, perfis declaradamente falsos e contas de suporte para as campanhas).

\section{Os candidatos continuam}

\section{não interagindo?}

Dilma Rousseff, José Serra e Marina Silva

distribuíram a aplicação de recursos para a interação discursiva em proporções distintas.

Enquanto Marina Silva dedicou 43,3\% de todos os seus tweets a menções e replicações, Dilma Rousseff os utilizou em 17,6\% de suas mensagens.
José Serra, por outro lado, fez da sua comunicação no Twitter um canal voltado majoritariamente para a interação com outros usuários. Das 1.687 mensagens publicadas pelo candidato do PSDB, 1.015 foram feitas com a utilização de mentions e retweets, ou seja, $60,2 \%$ de todos os tweets publicados.

Embora 0 candidato do PSDB se destaque na utilização dos dois recursos voltados a interações discursivas, a marca atingida por Marina Silva também é significativa. A candidata do PV dedicou quase metade de suas publicações a alguma forma de comunicação direta com outros usuários do Twitter.

Gráfico 1: José Serra - Quadro Geral - Interação Discursiva

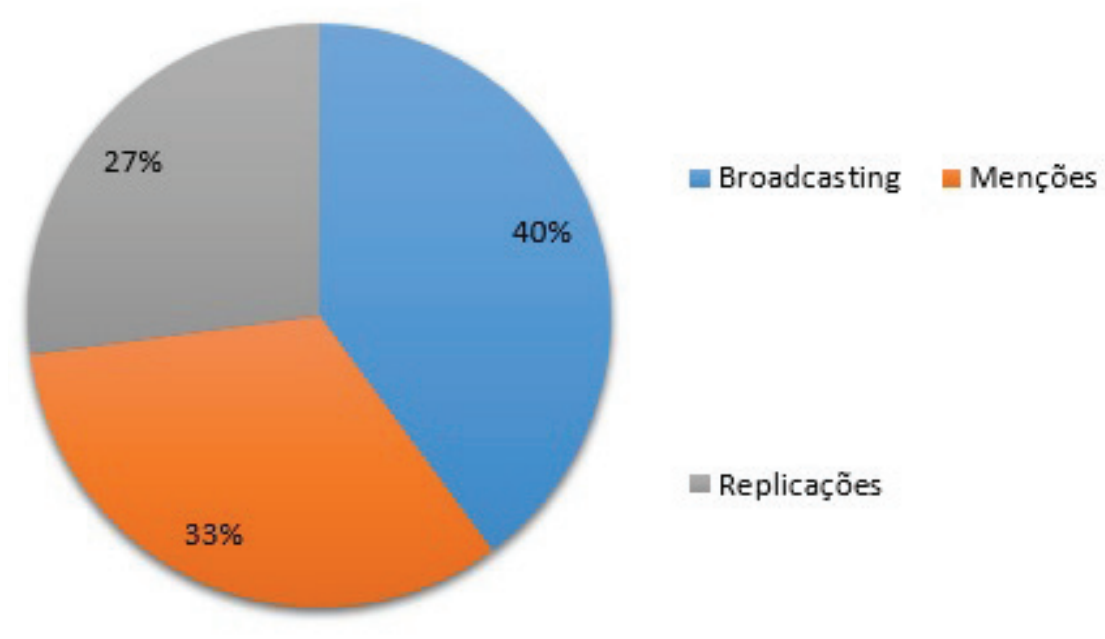


Gráfico 2: Marina Silva - Quadro Geral - Interação Discursiva

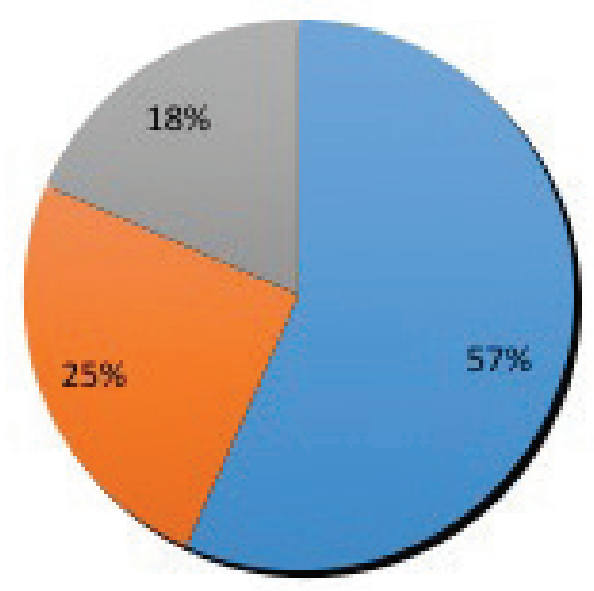

- Broadcasting $=$ Mençס̄es

= Replicaçôes

Dilma Rousseff não seguiu a tendência de seus dois concorrentes em 2010. A frequência de postagens com recursos para a interação ficou muito abaixo do índice de seus colegas. Como se pode observar no gráfico a seguir,
$82 \%$ de todas as suas publicações foram voltadas a enunciados sem quaisquer sinais de comunicação horizontal com outros usuários do Twitter. A grande parte, portanto, respeitou o modelo broadcasting.

Gráfico 3: Dilma Rousseff - Quadro Geral - Interação Discursiva

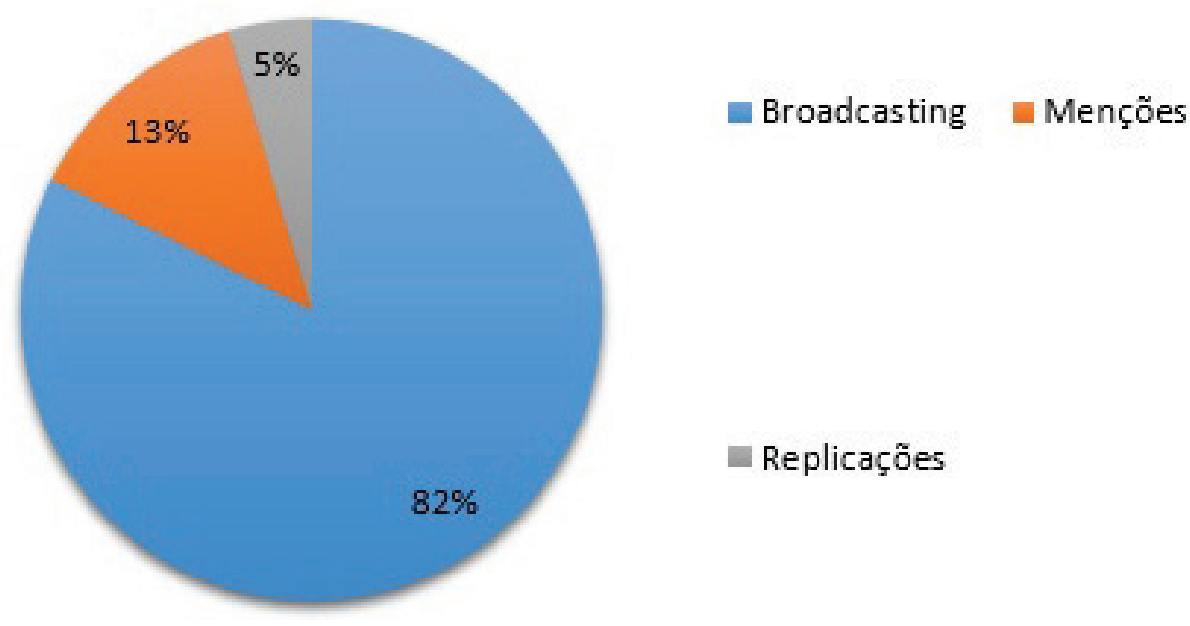


Considerando o conjunto de evidências empíricas de que se têm conhecimento neste trabalho, pode-se levar em conta que o padrão de campanha brasileiro no Twitter, a julgar pelo recorte das eleições presidenciais de 2010, se alinha às experiências com os maiores níveis de utilização de recursos para a interação discursiva (CONWAY, KENSKI, WANG, 2013; BRUNS, HIGHFIELD, 2013; GRAHAM et al., 2013; MACNAMARA, KENNING, 2010; ENLI, SKOGERBO, 2013).
Analisando os tweets publicados pelos três candidatos ao longo de todo o período da amostra, verifica-se que, dentre as 3.578 mensagens postadas, 1.732 foram compostas por mentions e retweets. Ou seja, levando em consideração esse somatório, constata-se que $48,4 \%$ da comunicação eleitoral dos três principais candidatos no Twitter sugerem algum tipo de interação discursiva entre campanhas e outros usuários do site, conforme exposto no gráfico a seguir.

Por razões diversas que serão discutidas nas Classificação funcional dos Tweets considerações finais deste artigo, as campanhas online, ao menos no que se refere à presença nos

\section{Marina Silva} sites para redes sociais e no caso em tela, não respeitam o padrão unidirecional que predominou Na soma das mensagens com menções ao longo dos anos anteriores ao advento e à e replicações de Marina Silva, destacapopularização dos social media. se a exibição de capital social como a 
estratégia principal, seguida de tweets

com posicionamentos, tentativa de criar

engajamento e temas informais contidos na

categoria "outros". É necessário salientar que, apesar da categoria "promessas e propostas"

não figurar entre as quatro primeiras, sua

diferença para a última melhor posicionada é de apenas cinco tweets. "Outros" representa a fatia de $15 \%$ do total, enquanto as mensagens contendo propostas representam 14\%, o que reforça a importância das interações discursivas para a discussão de temas políticos na campanha de Marina Silva.
No entanto, faz-se necessário salientar que,

isolando apenas os tweets contendo menções a outros perfis, a categoria "posicionamento" figura como a prioridade da comunicação de Marina Silva no Twitter. A então candidata do Partido Verde interagiu, através de menções, com o intuito de esclarecer seus posicionamentos, em primeiro lugar, seguido de promessas e propostas, mensagens classificadas como "outros" e aquelas voltadas ao engajamento. Há, dessa forma, evidências de que Marina Silva tratou de questões políticas caras à sua candidatura e à sua campanha nas interações com outros perfis do Twitter. 


\section{José Serra}

Na análise do conjunto das duas formas de interação discursiva, foi possível constatar que José Serra manteve o padrão de distribuição dos tweets contendo menções, ao contrário de Marina Silva. Na soma das mensagens contendo mentions e retweets, a interação entre o perfil de José Serra e outros perfis priorizou: (a) temas triviais e apolíticos (outros); (b) exibição de capital social, (c) agenda e (d) informações de caráter pessoal e íntimo, conforme apresentado na Figura $n^{0} 24$.

A única diferença para o ranking da categoria de mensagens contendo menções é a inversão de posições de tweets voltados para a exibição de capital social e aqueles voltados para a "agenda" do candidato. No comparativo com Marina Silva, portanto, insinua-se uma tendência do uso de interações discursivas para agradecer, enaltecer ou simplesmente exibir manifestações de apoio, elogios e enunciados advindos de outros perfis que destaquem qualidades do candidato. 27\% das mensagens contendo retweets e mentions de José Serra foram dedicadas à exibição de capital social.

0 fato de 0 candidato tucano ter dedicado mais de $60 \%$ de todos os seus tweets a algum tipo de interação discursiva com outros usuários do Twitter fez com que, evidentemente, a distribuição categórica de suas mensagens contendo menções e replicações fosse um espelho do ranking das categorias aplicadas a todos os seus tweets.

\section{Dilma Rousseff}

A candidata do PT dedicou apenas 69 de todos os seus 392 tweets para a inserção de recursos de interação discursiva. Dado o baixo índice de mensagens contendo menções e replicações, algumas categorias de conteúdo não foram contempladas sequer uma vez. No tocante à funcionalidade das mensagens contendo apenas menções, a candidata do PT inverteu a tendência esboçada por seus dois adversários.

Na distribuição geral dos recursos para a interação discursiva de Dilma Rousseff, predominou a ocorrência da função informal "outros", em primeiro lugar, e exibição de capital social em segundo. As categorias "divulgação de notícias", "tentativas de criar engajamento" e "promessas e propostas" não foram contempladas em nenhuma ocasião de publicação das mensagens com menções e com replicações.

Na distribuição geral dos recursos para a interação discursiva entre os três candidatos, predominaram as funções de "exibição de capital social" e temas informais representados pela categoria "outros". As categorias "divulgação de notícias", "tentativas de criar engajamento" e "promessas e propostas" não foram contempladas em nenhuma ocasião de publicação das mensagens com menções e com replicações.

Somando as mensagens contendo replicações e menções dos três candidatos, percebe-se que as 


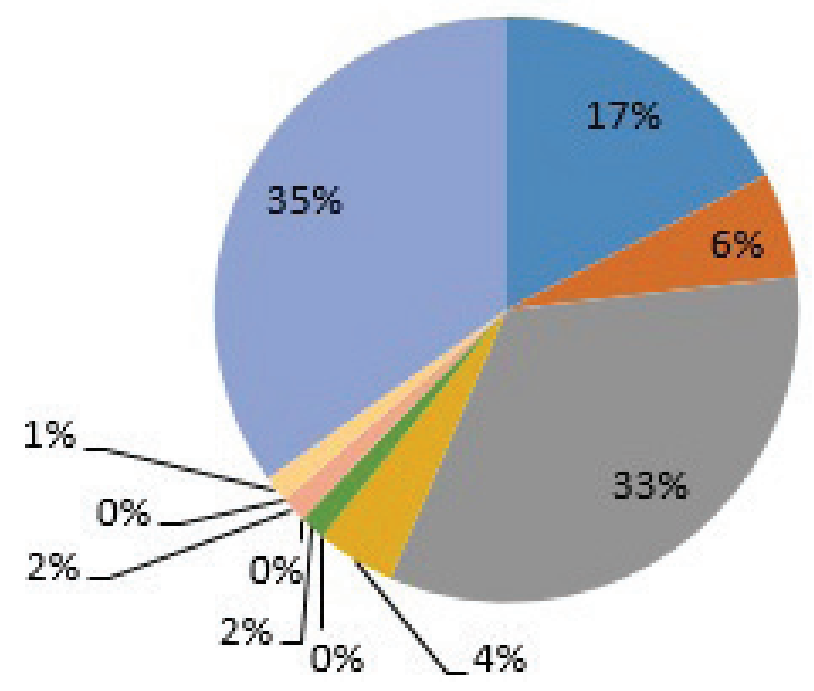

agenda

Exibição de Capital Político

n Exibição de Capital Social

- Posicionamento

- Divulgação de Notícias

n Campanha Negativa

- Tentativa de Criar Engajamento

a Pessoal/Intimidade

- Promessas e Propostas

Realizações Passadas

noutros

Gráfico 7: Quadro Geral - Análise de conteúdo dos recursos para interação discursiva

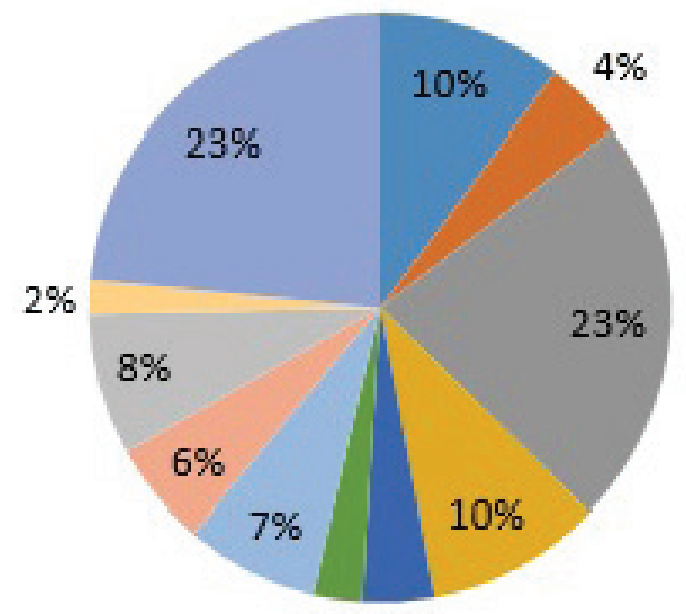

$3 \% 4 \%$ agenda

- Exibição de Capital Político

Exibição de Capital Social

- Posicionamento

Divulgação de Notícias

- Campanha Negativa

- Tentativa de Criar Engajamento

Pessoal/Intimidade

- Promessas e Propostas

Realizações Passadas

Outros 
interações discursivas serviram, majoritariamente, ao propósito de exibição de capital social (23\%) e considerações sobre temas aleatórios externos à política. Em seguida, figuraram as categorias "agenda" e "posicionamento", cada uma com 10\%. "Promessas e propostas" foi responsável por apenas $8 \%$ da interação entre campanhas e eleitores.

Os dados dos três candidatos sugerem haver padrões aproximados de correspondência dos dois recursos para interações discursivas. Embora José Serra tenha sido o candidato que se destacou na utilização das menções e replicações para definir 0 estilo da comunicação de campanha no Twitter, a então candidata do Partido Verde, Marina Silva, mereceu destaque, uma vez que, no que se refere às interações com o uso de menções, sua campanha optou por contemplar mensagens relacionadas à discussão de posicionamentos e propostas.

Pode-se questionar, com absoluta razão, que a simples identificação de mentions e retweets não é suficiente para afirmar que as campanhas, de fato, interagiam. Afinal, menções podem ser simples menções, sem qualquer traço de interação discursiva ou reciprocidade, e replicações de mensagens podem ser meras reproduções de tweets de terceiros. Desse modo, foi desenvolvida uma análise para que essas mensagens fossem distinguidas e as interações efetivas fossem identificadas.
A verificação da presença genuína de interação nas postagens dos três candidatos foi feita a partir de uma tipologia relativamente simples. Foram criados dois indicadores para as variáveis Menção e Replicação. São elas: Interação e Menção/ Reprodução. Isto porque a simples constatação de mention e retweets pode mascarar mensagens sem quaisquer interações discursivas, como é 0 caso, por exemplo, da menção a perfis de veículos de comunicação com o intuito de divulgar alguma atividade de agenda ou apenas mencionar 0 endereço dos perfis de algum usuário, ao invés de citar seus nomes.

\section{Retweets são recursos que possibilitam} interações discursivas, mas também são, por excelência, o mecanismo para que usuários do Twitter compartilhem mensagens e informações publicadas por terceiros, com o intuito de endossar o conteúdo do tweet reproduzido e repassar a seus seguidores. Todos os três candidatos, em alguma medida, utilizaram tal recurso com essa finalidade.

\section{Entretanto, os recursos para a interação} discursiva podem ser empregados, efetivamente, para interagir discursivamente, e este é o foco das análises que seguem.

Foram consideradas como interações discursivas quaisquer mensagens cujos enunciados contivessem respostas ou quaisquer reações discursivas dos candidatos ao mencionar um perfil ou reproduzir mensagens de terceiros. Marina Silva foi a candidata 
que mais, realmente, interagiu. $90 \%$ das menções feitas pela candidata e 70\% das mensagens com replicações contiveram interações discursivas.

José Serra vem em segundo. No universo das menções, $82,2 \%$ das mensagens, de fato, contemplaram discursivamente manifestações de terceiros. No que tange aos retweets, $61,10 \%$ se constituíram como interações discursivas. No total, $72,2 \%$ de todas as mensagens contendo recursos para a interação discursiva efetivamente serviram a esse propósito. Dilma Rousseff interagiu em $78,4 \%$ das mensagens contendo menções e em $55,6 \%$ das publicações contendo retweets. Na soma geral das menções e replicações, a candidata do PT estabeleceu interações discursivas em 72,4\% das vezes.

Desse modo, conforme exposto no gráfico a seguir, foi possível identificar que, do conjunto das mensagens contendo os recursos para interações discursivas, 72,4\% serviram, realmente, à interação discursiva.

\section{Perfis dos interlocutores}

Como já exposto, foram criadas cinco categorias para distinguir os interlocutores selecionados pelas campanhas para interagir discursivamente. Basicamente, foram separados perfis de agentes e instituições da política, celebridades, cidadãos (eleitores, simpatizantes e militantes), agentes e

Gráfico 8: Quadro Geral - Interações Discursivas Efetivas

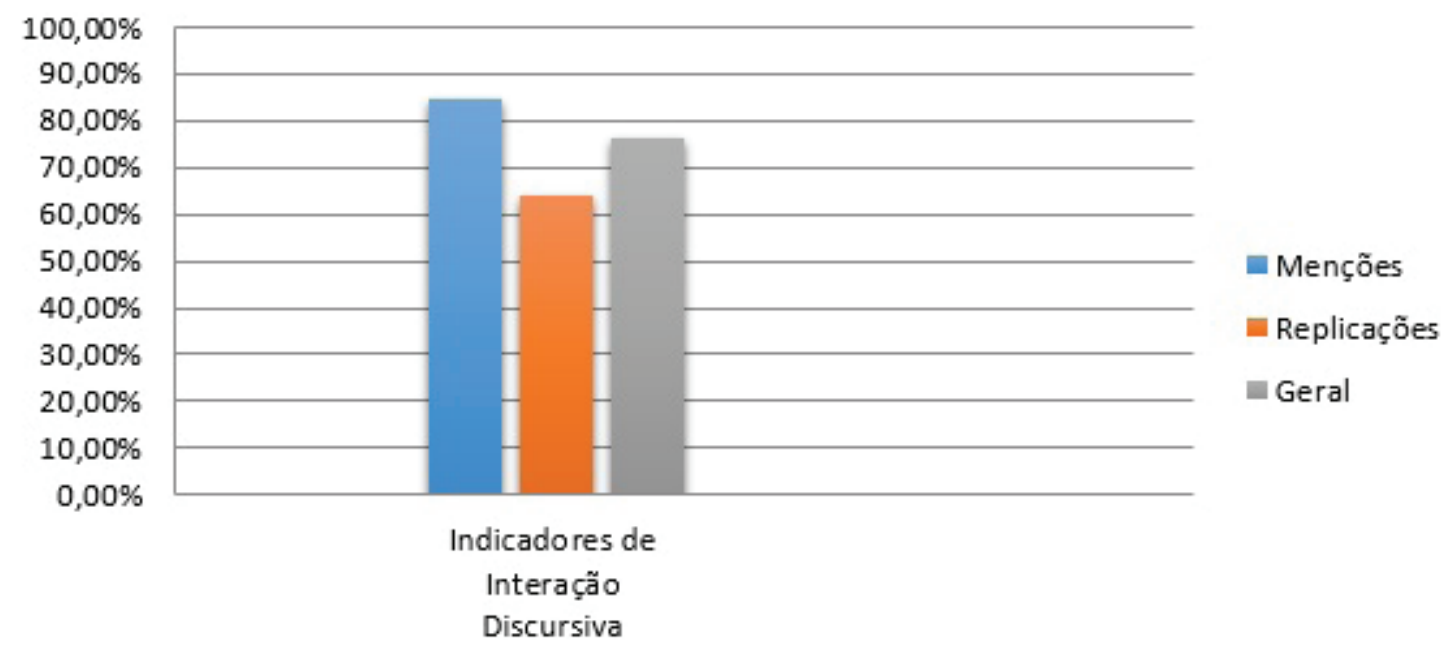


agências do jornalismo (jornalistas, contas de veículos de comunicação, blogs independentes), "fakes" e "outros" (grupos organizados, perfis declaradamente falsos e contas de suporte para as campanhas).

\section{Marina Silva}

A campanha da candidata do Partido Verde priorizou majoritariamente a interação com cidadãos "comuns". A discrepância entre esses perfis e todos os outros é significativa: $82 \%$ dos interlocutores de Marina Silva foram constituídos de eleitores, simpatizantes ou militantes.

Celebridades representaram $4 \%$ dos contemplados, assim como agentes e instituições do jornalismo, e apenas $3 \%$ foram identificados como "fakes". Cerca de $5 \%$ foram classificados na categoria "outros", em que se enquadraram perfis de grupos de advocacia dos interesses da esfera civil, perfis oficiais de apoio a campanhas e perfis "fakes" autodeclarados.

Agentes políticos figuraram em patamar parecido:

$2 \%$. Ao contrário de impressões e suspeitas iniciais - que se julga aqui procedente -, 0 artifício de utilização de perfis falsos para simular interlocuções não representou nada na campanha de Marina Silva. Ao contrário: cidadãos comuns foram os reais interlocutores da candidata do PV.

\section{José Serra}

Em termos absolutos, José Serra contemplou um número maior de cidadãos comuns em comparação à Marina Silva. 681 perfis figuraram nas mensagens do candidato do PSDB contra 661 da candidata do PV. Percebe-se que Serra registrou uma proporção maior da categoria "outros" em comparação à Marina. Este fato se deu em razão do candidato tucano ter interagido com perfis oficiais de apoio à sua campanha com maior frequência.

A proporção de perfis falsos também foi ínfima, comparativamente. A distribuição geral evidencia que 0 candidato do PSDB priorizou o contato direto com eleitores que serviram, segundo sugerem as análises de conteúdo das mensagens do candidato, para a exibição de capital social.

\section{Dilma Rousseff}

A candidata do PT destoa mais uma vez de seus dois adversários no uso que fez do Twitter. Dilma

Rousseff teve muito mais interlocutores da esfera da política institucional do que os outros dois candidatos. A grande maioria dos interlocutores contemplados nesta categoria foi composta por aliados da candidata do PT, como Eduardo Campos, 0 candidato a vice-presidente Michel Temer e 0 seu colega de partido Aloizio Mercadante.

Na situação peculiar de Dilma Rousseff, que, pela primeira vez, disputava um cargo eletivo, a estratégia de mostrar apoio político e alianças partidárias se fazia muito mais necessária do que nos casos de seus dois adversários. As interações discursivas da candidata refletiram sua condição política peculiar. Houve, também, um número 
muito maior de perfis falsos que ajudaram a candidata a exibir capital social. Entretanto, tornam-se relativamente desimportantes porque, em sua maioria, foram mencionados em publicações de agradecimentos ao lado de tantos outros tantos perfis reais.

A maior parte das interações discursivas de Dilma Rousseff voltou-se a cidadãos comuns (54\%), 0 que reforça a tendência da eleição para presidente de 2010 no Twitter ter sido voltada para a comunicação com o eleitor comum nos perfis dos três principais candidatos.

Todos os perfis mencionados em mensagens contendo recursos para a interação discursiva dos três candidatos foram unificados e submetidos a uma triagem para excluir duplicatas, a fim de que fosse alcançado o número exato de interlocutores contemplados durante o período da amostra. De modo geral, o número de duplicatas em todas as categorias foi baixo. Isso demonstra que, ao menos na dimensão dos recursos para a interação discursiva, os três candidatos se comunicaram com redes sociais distintas no Twitter. No cruzamento entre as categorias voltadas para a interlocução com cidadãos comuns, foram subtraídos apenas 16 perfis em razão de duplicações, o que correspondeu a 1430 perfis mencionados na soma das três campanhas ou $75 \%$ de conjunto total de interlocutores contemplados nos perfis dos candidatos, conforme exposto no Gráfico 9.

Gráfico 9: Quadro Geral - Perfis dos Interlocutores

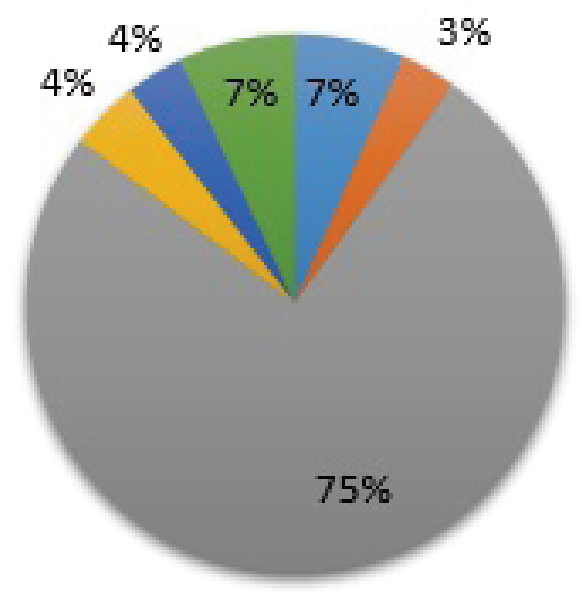

Agentes e Instituições Políticas

Celebridades

Cidadãos comuns

Jornalismo

Fakes 
No quadro geral, a proporção de interlocutores com perfis falsos manteve uma média baixa (4\%), e a interação com agentes e instituições políticas e perfis da categoria "outros" se equivaleram, cada um com 7\%. Percebe-se na análise dos dados que a estratégia de interagir discursivamente com celebridades para fins de exibição de prestígio foi praticamente ignorada. Interações com celebridades representaram apenas $3 \%$ do conjunto de interlocutores acionados ou contemplados pelos perfis das campanhas.

Os dados demonstram, de forma substantiva, que, na dimensão interativa da comunicação das três campanhas, o Twitter funcionou para aproximar candidatos e suas equipes a eleitores comuns, principalmente - como foi demonstrado em seções anteriores - para exibir capital social e tratar de temas informais externos à política.

\section{Considerações finais}

A pergunta feita por Jennifer Stromer-Galley, há 15 anos, carece de reformulação. Uma vez inseridas em plataformas digitais cuja sociabilidade se define não apenas pelo consumo de informações e manifestações de opinião isoladas, mas, também, pelas interações discursivas, as campanhas políticas passam a se comportar, em certa medida, como os usuários desses ambientes. Outra questão se coloca: não se trata, apenas, de verificar se partidos, candidatos e membros de campanha estão interagindo, mas como, com qual propósito e com quem interagem.
0 objetivo desta pesquisa foi 0 de lançar luz sobre estes aspectos no contexto brasileiro, mais especificamente nas primeiras eleições presidenciais em que a utilização dos social media por campanhas políticas foi autorizada pela Justiça Eleitoral. Os dados encontrados nesta pesquisa, bem como em outras análises, como no contexto australiano apresentado por Graham et al. (2013), demonstram que aquele cenário fotografado por Jennifer Stromer-Galley em 2000, que se perpetuou por anos, já não se faz mais presente em sua integralidade. Ressaltase que este trabalho oferece uma perspectiva metodológica que permite afirmar, com menor margem de erro, o quão realmente interativas foram as campanhas analisadas.

Conforme os resultados apresentados neste artigo, as três principais campanhas para presidente do Brasil no Twitter dedicaram, em conjunto, quase metade de suas mensagens à utilização dos recursos para interação discursiva (48\%). E deste somatório, quase 80\% se constituíram de interações efetivas. Conforme mencionado anteriormente, embora análises empreendidas em outros contextos nacionais apontem, também, para um índice considerável de interações por parte de campanhas eleitorais no Twitter, a consideração desses resultados sugere uma mudança de perspectiva de candidatos e partidos no tocante aos potenciais interativos da comunicação digital. Em especial, o caso brasileiro analisado se destaca pelos índices apresentados. 
Trata-se de uma marca significativa, mas que deve ser ponderada sobre outras premissas e questões teóricas que permeiam 0 fenômeno das campanhas online. Como demonstrado nas análises empreendidas, apenas a candidata Marina Silva, do Partido Verde, dedicou a maior parte da comunicação direta que estabeleceu com eleitores para esclarecer e discutir ideias. No quadro geral das interações discursivas dos três candidatos, predominou, majoritariamente, a abordagem de assuntos informais, como estratégia de aproximação do eleitor a partir de temas presentes em seus cotidianos ou simples considerações acerca de temas irrelevantes sob 0 ponto de vista político.

Esta constatação demonstra que, apesar de 0 Twitter ter sido usado significativamente para a comunicação horizontal, os três candidatos pouco contribuíram para concretizar uma das reivindicações teóricas que se faz às campanhas políticas nos meios digitais: promover a troca argumentativa entre candidatos e cidadãos acerca de temas políticos relevantes na agenda do debate público, gerando ganhos cognitivos e, consequentemente, políticos para as partes envolvidas e para o próprio processo políticoeleitoral. Trata-se, portanto, da reivindicação por maior participação cidadã no jogo político, a começar pela disputa eleitoral. Essa formulação teórica ou reivindicação política que permeia 0 fenômeno das campanhas online desde sua origem permanece, ainda, na dimensão do idealismo.
Contudo, há que se notar que tanto José Serra quanto Marina Silva fizeram referências à possibilidade de eleitores contribuírem com suas plataformas em sites colaborativos criados por suas campanhas. Portanto, existiu uma dimensão participativa tanto na campanha digital de Marina Silva quanto na de José Serra (AGGIO, MARQUES, SAMPAI0, 2011), mas que extrapola o objetivo da pesquisa apresentada aqui. No que se refere aos interlocutores das campanhas, a faixa de $75 \%$ de cidadãos "comuns" contemplados pelos três perfis dos presidenciáveis sugere algumas reflexões. A primeira é a de que a predileção estratégica das campanhas para acumular e exibir capital social não perpassa pelo contato direto com celebridades. Seria plausível admitir um volume maior desse tipo de contato pelo simples fato de personalidades públicas colecionarem exércitos de seguidores que poderiam tomar conhecimento da existência de uma campanha ou se aproximarem dela graças aos elogios e às recomendações de seus ídolos.

Parece existir, desse modo, uma questão conceitual de que 0 Twitter deve contemplar em seus endereçamentos 0 eleitor comum em níveis elevados de comunicação horizontal, mas também uma questão pragmática na medida em que 0 contingente mais expressivo de usuários deve, naturalmente, ser 0 alvo de investidas que visam à ampliação da visibilidade das campanhas. Manter estratégias que sustentem vínculos afetivos com usuários do Twitter pode significar investir em pequenos elementos que, somados e 
espalhados em redes sociais diversas, podem fazer a diferença em ações de mobilização que gerem reconhecimento e votos.

A suposição de que 0 contato direto com jornalistas e veículos de comunicação poderia funcionar como uma estratégia recorrente também não se sustenta. Para tentar influenciar a cobertura jornalística a seu favor, basta que as campanhas utilizem o Twitter e produzam informações atrativas aos critérios de noticiabilidade do jornalismo. A excepcionalidade factual é uma delas. Marina Silva, por exemplo, conseguiu agitar as moléculas do Twitter a ponto de alçar o nome de sua campanha aos tópicos mais comentados do site por mais de uma vez.

Finalmente, candidatos e partidos parecem não mais evitar a interação que evitavam há alguns anos, e o contexto brasileiro reforça essa suposição. Características estruturais e sociais do Twitter parecem servir com variáveis que incidem sobre essa mudança, assim como sua composição demográfica, que fez com que os três principais candidatos priorizassem 0 contato direto com cidadãos "comuns", em detrimento de outros atores, instituições e agências. Resta, como esboçado anteriormente, identificar as razões pelas quais o debate político substantivo sobre projetos e plataformas ainda não se tornou o objetivo principal da comunicação horizontal dessas campanhas. Talvez aquelas razões identificadas por Jennifer Stromer-Galley se mantenham, talvez outras razões suprimam um caráter ainda mais participativo e substantivo nas campanhas online.

0 caso de Marina Silva suscita questões que devem ser melhor examinadas em pesquisas futuras, principalmente sob uma perspectiva comparativa com outros períodos eleitorais e contextos nacionais. Afinal, não se pode analisar o uso de tecnologias de comunicação sem considerar as variáveis de influência que lhe são externas e ajudam a moldá-las. No caso em questão, Marina Silva foi compelida a tratar de questões políticas, sugerindo uma demanda direta da opinião pública no Twitter, que pode ter caracterizado parte de suas estratégias de campanha.

\section{Referências}

AGGIO, Camilo; MARQUES, F. P. J. A.; SAMPAIO, R. C. Campanhas Online, Participação Política e Esfera Pública: 0 Caso do Plano de Governo Colaborativo nas Eleições Brasileiras de2010. In: João Carlos CORREIA; Rousiley MAIA. (Org.). Public Sphere Reconsidered: Theoriesand Practices. Covilhã, Portugal: Livros LabCom, v. 1. 2011, p. 3-21.

ARAGÓN, Pablo; KAPPLER, Karolin Eva; KALTENBRUNNER, Andreas; LANIADO, David; VOLKOVICH, Yana. Communication Dynamics in Twitter During Political Campaigns: The Case of the 2011 Spanish National Election. Policy and Internet. 5(2), 2013, p. 183-206.

BAXTER, Graeme; MARCELLA, Rita. Online Parliamentary Election Campaigns in Scotland: A decade of Research. E-Journal of eDemocracy and Open Government, 5(2), 2012, p. 107-127. 
BRUNS, Axel; HIGHFIELD, Tim. Political Networks on Twitter. Information, Communication \& Society, 16(5), 2013, p. 667-691.

CONWAY, Bethany Anne; KENSKI, Kate; WANG, Di. Twitter Use by Presidential Primary Candidates During the 2012 Campaign. American Behavioral Scientist, 57(11), 2013, p. 1596- 1610.

CRIAD0, J.I.; MARTINEZ-FUENTES, G.; SILVA, A. 2012. "Social Media for Political Campaigning. The Use of Twitter by Spanish Mayors in 2011 Local Elections." In Web 2.0 Technologies and Democratic Governance. Political, Policy and Management Implications, New York: C.G. Reddick and S.K. Aikins, 2012, p. 219-32.

DAHLBERG, Lincoln. The Internet and Democratic Discourse. Exploring the prospects of online deliberative forums extending the public sphere. Information, Communication \& Society 4 (4), 2001, p. 615-633.

DRUCKMAN, James N.; KIFER, Martin J; PARKIN, Michael. The Technological Development of Congressional Candidate Websites: How and Why Candidates Use Web Innovations. Social Science Computer Review; 25 (4), 2007, p. 425-442.

ENLI, Gunn Sara; SKOGERBO, Eli. Personalized Campaigns in Party-Centred Politics. Information, Communication \& Society, 16 (5),2013, p. 1-18

FARNSWORTH, Stephen J.; OWEN, Diana. Internet use and the 2000 presidential election. Electoral Studies, 23 (3), p. 415-429, 2004.

FERNANDEZ, Rogério Garcia. Campanhas Eleitorais Brasileiras na Internet. Tese de mestrado apresentada ao Departamento de Ciência Política do Instituto de Filosofia e Ciência Política do Instituto de Filosofia e Ciências Humanas da Universidade Estadual de Campinas. Campinas, 2005.

GIBSON, Rachel K.; MARGOLIS; RESNICK, Michael; WARD, Stephen J. Election campaigning on the www in the USA and UK: A Comparative Analysis. Party Politics, 9 (1), p. 47-75, 2003.
GOMES, W.; REIS, Lucas; DUARTE, Marília; MARQUES, Maurício. 0 Twitter na campanha eleitoral de 2010. Anais do IV Congresso da Compolítica. Rio de Janeiro. 2011.

GRAHAM, Todd; BROERSMA, Marcel; HAZELHOFF, Karin; van't Haar, GUID0. Between Broadcasting Political Message and Interacting with Voters. Information, Communication \& Society, 2013, p. 692-716.

KAID, Lynda Lee; POSTELNICU, Monica. Political Advertising in the 2004 Election:

Comparison of Traditional Television and Internet Messages. American Behavioral Scientist; 49 (2); p. 265-278, 2005.

LUSOLI, Wainer e WARD, Janelle. "Politics Makes Strange Bedfellows": The Internet and the 2004 European Parliament Election in Britain. The Harvard International Journal of Press/Politics ; 10 (4); 71-97, 2005.

MACNAMARA, Jim; KENNING, Gail. E-electioneering 2010: Trends in social media use in Australian political communication. Disponível em: https:/www.academia. edu/830297/Eelectioneering_2010_Trends_in_Social_ Media_Use_in_Australian_Political_Communication. Acesso em 01/05/2014.

PARK, Hun Myoung; PERRY, James L. Do Campaign Websites Really Matter in Electoral Civic Engagement? Empirical Evidence From the 2004 Post-Election Internet Tracking Survey. Social Science Computer Review, 26(2), 2008, p. 190-212.

MANOHARAN, A.; HOLZER, M (Orgs.). E-governance and Civic Engagement: Facts and determinants of e-democracy, Pennsylvania: Information Science Reference, 2012.

SCHWEITZER, Eva Johanna. Election Campaigning Online: German Party Websites in the 2002 National Elections. European Journal of Communication; 20 (3); p. 327-351, 2005. 
STROMER-GALLEY, Jennifer. Interação on-line e por que os candidatos a evitam. In: MARQUES, F., P., A.; SAMPAIO, R., C.; Aggio, Camilo (Org.). Do Clique à Urna: internet, redes sociais e eleições no Brasil. Salvador: EDUFBA, v. 1, p. 29-62. 2013.

TKACH-KAWASAKI, Leslie M. Politics@Japan: Party Competition on the Internet in Japan. Party Politics, 9(1), 2003, p. 105-123.

WARD, Stephen e GIBSON, Rachel. On-line and on message? Candidate websites in the 2001 General Election. British Journal of Politics and International Relations, 5(2), 2003, p. 188-205. 


\section{Candidates still avoid online interaction? An analysis of how and with whom 2010 Brazilian presidential candidates interacted on Twitter}

\section{Abstract}

In 2000, Jennifer Stromer-Galley published the paper "On-line interaction and why candidates avoid it". It discusses how often and why candidates avoided direct interaction between them and citizens through campaign websites in 1996 and 1996 American elections. Empirical evidences suggest that Stromer-Galley's findings became a pattern in many countries over the years. This paper discusses how social media transforms this unidirectional pattern into dialogical actions. This discussion is supported by analyzes of tweets posted by the three main presidential candidates in 2010 Brazilian presidential election on Twitter.

\section{Keywords}

Elections; Online Campaigning; Twitter

\section{Candidatos impiden una mayor interacción? Twitter, Comunicación horizontal y Elecciones brasileñas}

\section{Resumen}

A lo largo de la constitución de la literatura sobre las campañas en línea, el tema de la interacción se ha convertido en una de las investigaciones más relevantes y empírica ha demostrado que los candidatos tienden a evitar la interacción directa con los votantes a través de los años y en diferentes países, como se indica investigador Jennifer Stromer -Galley en 2000. Este documento analiza los cambios potenciales y reales este escenario con la integración de los medios sociales en la estrategia de campaña, centrándose en el análisis de la forma interactiva son los perfiles oficiales de las tres principales candidatos a la presidencia de Brasil en 2010 y en Twitter ¿Qué perfiles de las partes contempladas en estas interacciones.

\section{Palabras clave}

Elecciones; Campañas online; Twitter 


\section{Expediente}

A revista E-Compós é a publicação científica em formato eletrônico da Associação Nacional dos Programas de Pós-Graduação em Comunicação (Compós). Lançada em 2004, tem como principal finalidade difundir a produção acadêmica de pesquisadores da área de Comunicação, inseridos em instituições do Brasil e do exterior.

\section{E-COMPÓS I www.e-compos.org.br I E-ISSN 1808-2599}

Revista da Associação Nacional dos Programas de Pós-Graduação em Comunicação.

Brasília, v.18, n.1, jan./abri.. 2015.

A identificação das edições, a partir de 2008, passa a ser volume anual com três números.

\section{CONSELHO EDITORIAL}

Alexandre Rocha da Silva, Universidade Federal do Rio Grande do Sul, Brasil Alexandre Farbiarz, Universidade Federal Fluminense, Brasil Ana Carolina Damboriarena Escosteguy, Pontifícia Universidade Católica do Rio Grande do Sul, Brasil

Ana Carolina Rocha Pessôa Temer, Universidade Federal de Goiás, Brasil Ana Regina Barros Rego Leal, Universidade Federal do Piauí, Brasil André Luiz Martins Lemos, Universidade Federal da Bahia, Brasil Andrea França, Pontifícia Universidade Católica do Rio de Janeiro, Brasil Antonio Carlos Hohlfeldt, Pontifícia Universidade Católica do Rio Grande do Sul, Brasil

Arthur Ituassu, Pontifícia Universidade Católica do Rio de Janeiro, Brasil Álvaro Larangeira, Universidade Tuiuti do Paraná, Brasil Ângela Freire Prysthon, Universidade Federal de Pernambuco, Brasil César Geraldo Guimarães, Universidade Federal de Minas Gerais, Brasil Cláudio Novaes Pinto Coelho, Faculdade Cásper Líbero, Brasil Daisi Irmgard Vogel, Universidade Federal de Santa Catarina, Brasil Daniela Zanetti, Universidade Federal do Espírito Santo, Brasil Denize Correa Araujo, Universidade Tuiuti do Paraná, Brasil Eduardo Antonio de Jesus, Pontifícia Universidade Católica de Minas Gerais, Brasil

Eduardo Vicente, Universidade de São Paulo, Brasil

Elizabeth Moraes Gonçalves, Universidade Metodista de São Paulo, Brasil Erick Felinto de Oliveira, Universidade do Estado do Rio de Janeiro, Brasil Francisco Elinaldo Teixeira, Universidade Estadual de Campinas, Brasil Francisco Paulo Jamil Almeida Marques, Universidade Federal do Ceará, Brasil Gabriela Reinaldo, Universidade Federal do Ceará, Brasil Gisela Grangeiro da Silva Castro, Escola Superior de Propaganda e Marketing, Brasil

Goiamérico Felício Carneiro Santos, Universidade Federal de Goiás, Brasil Gustavo Daudt Fischer, Unisinos, Brasil

Herom Vargas, Universidade Municipal de São Caetano do Sul, Brasil
Itania Maria Mota Gomes, Universidade Federal da Bahia, Brasil Janice Caiafa, Universidade Federal do Rio de Janeiro, Brasil Jiani Adriana Bonin, Universidade do Vale do Rio dos Sinos, Brasil José Afonso da Silva Junior, Universidade Federal de Pernambuco, Brasil José Luiz Aidar Prado, Pontifícia Universidade Católica de São Paulo, Brasil Kati Caetano, Universidade Tuiuti do Paraná, Brasil

Lilian Cristina Monteiro França, Universidade Federal de Sergipe, Brasil Liziane Soares Guazina, Universidade de Brasília, Brasil Luíza Mônica Assis da Silva, Universidade de Caxias do Sul, Brasil Luciana Miranda Costa, Universidade Federal do Pará, Brasil Malena Segura Contrera, Universidade Paulista, Brasil Marcel Vieira Barreto Silva, Universidade Federal da Paraíba, Brasil Maria Ogécia Drigo, Universidade de Sorocaba, Brasil Maria Ataide Malcher, Universidade Federal do Pará, Brasil Maria Clotilde Perez Rodrigues, Universidade de São Paulo, Brasil Maria das Graças Pinto Coelho, Universidade Federal do Rio Grande do Norte, Brasil

Mauricio Ribeiro da Silva, Universidade Paulista, Brasil

Mauro de Souza Ventura, Universidade Estadual Paulista, Brasil Márcio Souza Gonçalves, Universidade do Estado do Rio de Janeiro, Brasil Micael Maiolino Herschmann, Universidade Federal do Rio de Janeiro, Brasil Mirna Feitoza Pereira, Universidade Federal do Amazonas, Brasil Nísia Martins Rosario, Universidade Federal do Rio Grande do Sul, Brasil Potiguara Mendes Silveira Jr, Universidade Federal de Juiz de Fora, Brasil Regiane Ribeiro, Universidade Federal do Paraná, Brasil Rogério Ferraraz, Universidade Anhembi Morumbi, Brasil Rose Melo Rocha, Escola Superior de Propaganda e Marketing, Brasil Rozinaldo Antonio Miani, Universidade Estadual de Londrina, Brasil Sérgio Luiz Gadini, Universidade Estadual de Ponta Grossa, Brasil Simone Maria Andrade Pereira de Sá, Universidade Federal Fluminense, Brasil Veneza Mayora Ronsini, Universidade Federal de Santa Maria, Brasil Walmir Albuquerque Barbosa, Universidade Federal do Amazonas, Brasil

\section{COMISSÃO EDITORIAL}

\section{Cristiane Freitas Gutfreind}

Pontifícia Universidade Católica do Rio Grande do Sul, Brasil

Irene Machado

Universidade de São Paulo, Brasil

Jorge Cardoso Filho

Universidade Federal do Reconcavo da Bahia, Brasil

Universidade Federal da Bahia, Brasil

$$
\begin{aligned}
& \text { REVISÃo DE TEXTOS I Press Revisão } \\
& \text { SECRETÁRIA EXECUTIVA I Helena Stigger } \\
& \text { EDITORAÇÃO ELETRÔNICA I Roka Estúdio }
\end{aligned}
$$

COMPÓS I www.compos.org.br

Associação Nacional dos Programas de Pós-Graduação em Comunicação

Presidente

Eduardo Morettin

Universidade de São Paulo, Brasil

eduardomorettin@usp.br

Vice-presidente

Inês Vitorino

Universidade Federal do Ceará, Brasil

ines@ufc.br

Secretária-Geral

Gislene da Silva

Universidade Federal de Santa Catarina, Brasil gislenedasilva@gmail.com 